\title{
Transition State Infrared Spectra for the Trans $\rightarrow$ Cis Isomerization of a Simple Peptide Model
}

\author{
M. A. Sahai ${ }^{\mathrm{a}, *}$, M. Szori $^{\mathrm{b}}$, B. Viskolcz ${ }^{\mathrm{b}}$, E. F. Pai ${ }^{\mathrm{a}, \mathrm{c}}$ and I.G.Csizmadia ${ }^{\mathrm{b}, \mathrm{d},}$ \\ ${ }^{a}$ Department of Medical Biophysics, University of Toronto, Toronto Medical Discovery Tower, \\ 101 College Street, Rm. 5-359, Toronto, Ontario, Canada, M5G 1L7 \\ ${ }^{b}$ Department of Chemistry and Chemical Informatics, Faculty of Education, University of Szeged \\ Boldogasszony sgt. 6, Szeged, Hungary, 6725 \\ ${ }^{c}$ Department of Biochemistry and Molecular and Medical Genetics, University of Toronto, \\ Toronto, Ontario Canada, M5S 1A8 \\ ${ }^{\mathrm{d}}$ Department of Chemistry, University of Toronto, 80 St. George St., Toronto, Ontario, Canada, M5S 3H6
}

\section{SUPPORTING INFORMATION}

Figure A. Molecular structures of the MeCO-NHMe species

Table A. Z-matrix connectivity for the small peptide model MeCO-NHMe

Table B. Input structure parameters for the differing species of $\mathrm{MeCO}-\mathrm{NHMe}$

Table C. Output structure parameters for the differing species of MeCO-NHMe 

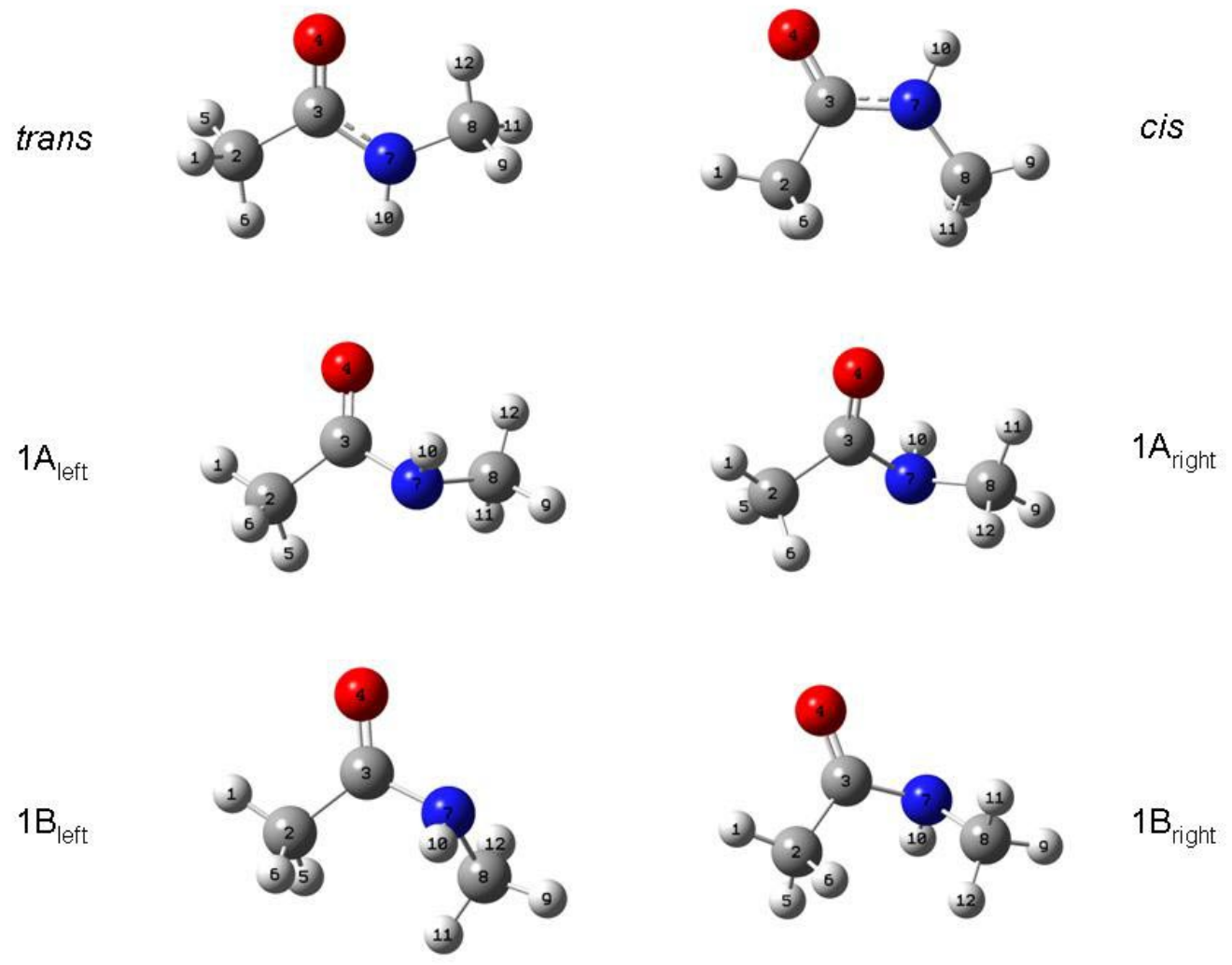

Figure A. Molecular structures of the MeCO-NHMe species 
Table A. Z-matrix connectivity for the small peptide model MeCO-NHMe
$\mathrm{H}$
C 1 R2
C 2 R3 1 A3
O 3 R4 2 A4 1 D4
H 2 R5 3 A5 4 D5
H 2 R6 3 A6 4 D6
N 3 R7 2 A7 1 D7
C 7 R8 3 A8 2 D8
H 8 R9 7 A9 3 D9
H 7 R10 3 A10 2 D10
H 8 R11 7 A11 3 D11
H 8 R12 7 A12 3 D12 
Table B. Input structure parameters for the differing species of MeCO-NHMe

\begin{tabular}{|l|r|r|r|r|r|r|}
\cline { 2 - 7 } \multicolumn{1}{c|}{} & \multicolumn{6}{c|}{ Species } \\
\hline Variable & trans & $\mathbf{1 B}_{\text {left }}$ & $\mathbf{1 B}_{\text {right }}$ & \multicolumn{1}{c|}{ cis } & $\mathbf{1 A}_{\text {left }}$ & $\mathbf{1 A}_{\text {right }}$ \\
\hline R2 & 1.08 & 1.07 & 1.09 & 1.07 & 1.07 & 1.07 \\
\hline R3 & 1.52 & 1.54 & 1.52 & 1.54 & 1.54 & 1.54 \\
\hline R4 & 1.22 & 1.21 & 1.21 & 1.22 & 1.21 & 1.21 \\
\hline R5 & 1.08 & 1.07 & 1.10 & 1.07 & 1.07 & 1.07 \\
\hline R6 & 1.08 & 1.07 & 1.10 & 1.07 & 1.07 & 1.07 \\
\hline R7 & 1.36 & 1.45 & 1.45 & 1.36 & 1.45 & 1.45 \\
\hline R8 & 1.46 & 1.47 & 1.47 & 1.47 & 1.47 & 1.47 \\
\hline R9 & 1.08 & 1.07 & 1.07 & 1.07 & 1.07 & 1.07 \\
\hline R10 & 0.99 & 1.02 & 1.00 & 1.01 & 1.02 & 1.02 \\
\hline R11 & 1.08 & 1.07 & 1.07 & 1.07 & 1.07 & 1.07 \\
\hline R12 & 1.08 & 1.07 & 1.07 & 1.07 & 1.07 & 1.07 \\
\hline A3 & 108.78 & 109.47 & 109.85 & 109.47 & 109.47 & 109.47 \\
\hline A4 & 123.51 & 121.70 & 121.90 & 123.07 & 121.70 & 121.70 \\
\hline A5 & 110.31 & 109.47 & 110.91 & 109.47 & 109.47 & 109.47 \\
\hline A6 & 110.31 & 109.47 & 110.48 & 109.47 & 109.47 & 109.47 \\
\hline A7 & 114.53 & 112.61 & 117.78 & 111.93 & 112.61 & 112.61 \\
\hline A8 & 120.25 & 107.02 & 108.36 & 119.19 & 107.02 & 107.02 \\
\hline A9 & 108.75 & 109.47 & 109.47 & 109.47 & 109.47 & 109.47 \\
\hline A10 & 120.45 & 107.02 & 114.79 & 121.81 & 107.02 & 107.02 \\
\hline A11 & 110.73 & 109.47 & 109.47 & 109.47 & 109.47 & 109.47 \\
\hline A12 & 110.73 & 109.47 & 109.47 & 109.47 & 109.47 & 109.47 \\
\hline D4 & 1.00 & 1.66 & -2.46 & 0.00 & -0.01 & -0.01 \\
\hline D5 & 120.09 & 121.66 & 118.32 & 120.00 & 119.99 & 119.99 \\
\hline D6 & -120.09 & -118.34 & -123.44 & -120.00 & -120.01 & -120.01 \\
\hline D7 & 179.00 & -178.34 & 177.04 & 180.00 & 179.99 & 179.99 \\
\hline D8 & 179.00 & 60.00 & -64.12 & 0.00 & 124.61 & -124.61 \\
\hline D9 & 179.00 & 155.80 & -180.00 & 180.00 & -166.38 & 166.38 \\
\hline D10 & 1.00 & -50.79 & 58.10 & -180.00 & -124.61 & 124.61 \\
\hline D11 & -59.96 & -84.20 & -60.00 & -60.00 & -46.38 & -73.62 \\
\hline D12 & 59.96 & 35.80 & 60.00 & 60.00 & 73.62 & 46.38 \\
\hline & & & & & & \\
\hline
\end{tabular}


Table C. Output structure parameters for the differing species of MeCO-NHMe

\begin{tabular}{|l|r|r|r|r|r|r|}
\cline { 2 - 7 } \multicolumn{1}{c|}{} & \multicolumn{6}{|c|}{ Species } \\
\hline Variable & trans & $\mathbf{1 B}_{\text {left }}$ & $\mathbf{1 B}_{\text {right }}$ & \multicolumn{1}{c|}{ cis } & $\mathbf{1 A}_{\text {left }}$ & $\mathbf{1}_{\text {right }}$ \\
\hline R2 & 1.09 & 1.09 & 1.09 & 1.09 & 1.09 & 1.09 \\
\hline R3 & 1.52 & 1.52 & 1.52 & 1.52 & 1.51 & 1.51 \\
\hline R4 & 1.22 & 1.21 & 1.21 & 1.22 & 1.21 & 1.21 \\
\hline R5 & 1.09 & 1.10 & 1.10 & 1.10 & 1.10 & 1.10 \\
\hline R6 & 1.09 & 1.10 & 1.10 & 1.10 & 1.10 & 1.10 \\
\hline R7 & 1.37 & 1.45 & 1.45 & 1.37 & 1.46 & 1.46 \\
\hline R8 & 1.45 & 1.47 & 1.47 & 1.45 & 1.48 & 1.48 \\
\hline R9 & 1.10 & 1.09 & 1.09 & 1.09 & 1.09 & 1.09 \\
\hline R10 & 1.01 & 1.02 & 1.02 & 1.01 & 1.02 & 1.02 \\
\hline R11 & 1.10 & 1.10 & 1.09 & 1.09 & 1.10 & 1.10 \\
\hline R12 & 1.09 & 1.09 & 1.10 & 1.10 & 1.10 & 1.10 \\
\hline A3 & 108.74 & 109.85 & 109.85 & 108.01 & 110.91 & 110.91 \\
\hline A4 & 121.71 & 121.90 & 121.90 & 122.49 & 123.77 & 123.77 \\
\hline A5 & 108.73 & 110.91 & 110.48 & 109.22 & 109.44 & 109.52 \\
\hline A6 & 114.06 & 110.48 & 110.91 & 109.10 & 109.52 & 109.44 \\
\hline A7 & 115.24 & 117.78 & 117.78 & 116.40 & 113.25 & 113.25 \\
\hline A8 & 122.57 & 114.79 & 114.77 & 127.23 & 111.32 & 111.32 \\
\hline A9 & 111.34 & 108.32 & 108.32 & 108.75 & 108.51 & 108.51 \\
\hline A10 & 118.74 & 108.36 & 108.34 & 113.16 & 105.77 & 105.77 \\
\hline A11 & 111.34 & 115.56 & 108.93 & 110.93 & 109.05 & 113.71 \\
\hline A12 & 107.09 & 108.92 & 115.56 & 113.11 & 113.71 & 109.05 \\
\hline D4 & -58.53 & -2.46 & 2.43 & 1.08 & 0.36 & -0.36 \\
\hline D5 & 57.98 & 118.32 & 123.41 & -121.55 & 122.36 & 121.65 \\
\hline D6 & 179.73 & -123.44 & -118.35 & 121.21 & -121.65 & -122.36 \\
\hline D7 & 121.45 & 177.04 & -177.07 & -179.96 & -179.38 & 179.38 \\
\hline D8 & -179.98 & 58.10 & -58.08 & 9.52 & 123.50 & -123.50 \\
\hline D9 & 119.28 & 175.79 & -175.85 & -167.55 & 175.21 & -175.21 \\
\hline D10 & 0.04 & -64.12 & 64.10 & 175.49 & -120.36 & 120.36 \\
\hline D11 & -119.15 & -62.84 & -59.26 & -49.50 & -67.70 & -53.39 \\
\hline D12 & 0.06 & 59.20 & 62.78 & 72.38 & 53.39 & 67.70 \\
\hline & & & & & & \\
\hline
\end{tabular}

